\title{
DC/DC converter control using suggested artificial intelligent controllers
}

\author{
Issa Ahmed Abed, Samar Hameed Majeed
}

Basrah Engineering Technical College, Southern Technical University, Basrah, Iraq

\begin{tabular}{|c|c|}
\hline Article Info & ABSTRACT \\
\hline Article history: & \multirow{10}{*}{$\begin{array}{l}\text { In order to provide constant DC voltage, buck converter is used which is a } \\
\text { common converter in different applications. The use of artificial control } \\
\text { methods for DC/DC converter will increase the productivity, spend low } \\
\text { energy, and able to avoid the changes. Here, in order to control the proposed } \\
\text { converter, intelligent regulation is utilized. Different methods have been } \\
\text { suggested to satisfy the need of the output. The work uses proportional- } \\
\text { integral-derivative (PID) controller which is received the error difference } \\
\text { between the output and the desired. Fuzzy logic controller (FLC) is also used. } \\
\text { While the fuzzy-PID supervised (FSC-PID) where the parameters of the PID } \\
\text { is updated using the fuzzy system. The explanation of the proposed controllers } \\
\text { is presented in this paper. PID, fuzzy logic controller, and fuzzy-PID } \\
\text { supervised have been designed and implemented using MATLAB in order to } \\
\text { settle the output of buck DC/DC converter. The complete system has been } \\
\text { built in MATLAB/Simulink. The proposed controller keeps track the output to } \\
\text { be exactly the set signal. }\end{array}$} \\
\hline Received Dec 19, 2020 & \\
\hline Revised Aug 13, 2021 & \\
\hline Accepted Aug 24, 2021 & \\
\hline Keywords: & \\
\hline Buck converter & \\
\hline Control & \\
\hline Duty cycle & \\
\hline Fuzzy logic & \\
\hline PID controller & \\
\hline
\end{tabular}

This is an open access article under the CC BY-SA license.

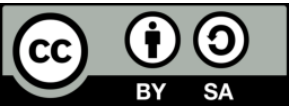

Corresponding Author:

Issa Ahmed Abed

Department of Control and Automation Engineering Techniques

Southern Technical University

Basrah, Iraq

Email: issaahmedabed@stu.edu.iq

\section{INTRODUCTION}

In view of the way that the energy of the solar is sustainable and condition well-disposed vitality source, the use of solar energy is quickly spreading [1]-[3]. One of the important parts in solar system is the DC/DC converters which are the interface between the source and the load. The usage of artificial intelligence in tackling and control different problems has been quickly looked into and examined in the course of recent decades [4]-[6]. The control process of DC/DC converter is considered as pivotal function in the conversion of power [7]. Where these converters have many important applications in our life such as aircrafts, computer power supplies, switching mode regulators, and solar chargers [7]. Martinez et al. [8] proposed output regulation for the DC/DC buck converter using fuzzy logic. They used type- 1 and type- 2 fuzzy logic. They presented simulation and experimentation for the voltage controller. In the second paper [9], the authors suggested fuzzy logic with buck converter. They showed the role of this controller and its applications in the control algorithm. They evaluated the buck under different loads and power quality indices like total harmonic distortion and power factor. Maji et al. [10], the authors suggested control method for buck converter utilizing fuzzy logic and robust controller. They used power metal oxide semiconductor field effect transistor (MOSFET) as a switch for the buck. On the other hands, the fuzzy and robust controller was based on pulse width modulation (PWM) to control the switch. The authors designed the fuzzy logic to enhance the converter by MATLAB/Simulink. However, when used the robust controller, the buck output 
continues constant even if the input change from $140 \mathrm{~V}$ to $340 \mathrm{~V}$. Pandey and Singh [11], have been controlled the non-isolated buck converter with proportional-integral-derivative (PID) controller. Where this controller measures the difference between process output and the set point. MATLAB simulation has been used to evaluate the performance of the buck. Patil and Jagtap [7], construct a system to control the buck converter. Where the authors controlled the output of the buck and keep constant without changing the load and the input. They utilize the adaptive fuzzy controller which simulated in MATLAB. They supposed that their control system will increase the efficiency and power of converter. Poodeh et al. [12], the authors introduce different fuzzy logic control law algorithms to control the DC/DC converter. They suggested these controllers to eliminate the overshoot and decrease the settling time. Fuzzy PI, fuzzy PD, and fuzzy PID are proposed for DC/DC converter. The work was done using MATLAB software. Corcau and Dinca [13], give a DC/DC buck converter controlled from $24 \mathrm{~V}$ to $12 \mathrm{~V}$ with $500 \mathrm{~W}$ power. The whole system is constructed in SIMPOWERSYS in MATLAB. They used fuzzy with PI configuration. In that case, the fuzzy controller is built for two controllers in parallel, the first one for proportional component and the second for integrative component. As mention they suggested this structure because of the less inference rules are needed as well as the tuning is easier. Priyadar Shini and Rai [14] designed PID controller for buck boost and Cuk DC/DC converters under the continuous conduction mode. They make the output constant with variations in the input. Safarinejadian and Jafartabar [15], they proposed control system for the output of the buck converter. They designed hybrid fuzzy logic controllers to perform this job. Three methods are used, fuzzy PI, two-level fuzzy hybrid, and fuzzy PD+I. They found that the PD+I have minimum steady state error. While the twolevel is suitable for less settling time. Ugale et al. [16], the authors suggested control for buck-boost DC/DC converter including a power semiconductor device as a switch. They develop a fuzzy logic produced the PWM pulse as a duty cycle of the MOSFET. This required to reach to the desired voltage. Duranay and Guldemir [17] proposed fuzzy control for DC/DC buck converter. Input voltage and output load are changed and the responses of fuzzy are tested in this work.

In this paper various controllers have been presented to control the duty cycle of the DC/DC buck converter for the closed loop system. The rest of the paper is organized as: section 2 presented the overview on buck converter; section 3 proposed the controllers; while the simulation results are in section 4; finally, the conclusion in section 5 .

\section{OVERVIEW ON BUCK CONVERTER}

The buck is a step down chopper converter. As in Figure 1, the input voltage is higher than that of the output. The switch is used for regulation and keep the desired level for the output. The switching frequency is the rate of change from $\mathrm{ON}$ to the $\mathrm{OFF}$ for this switch.

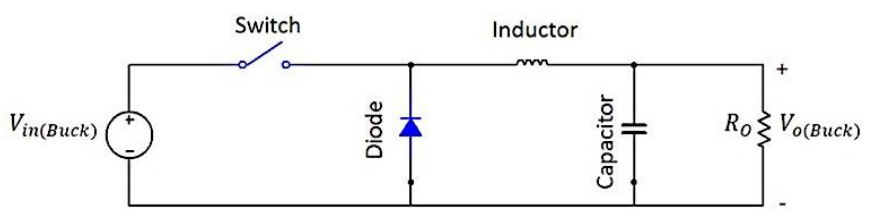

Figure 1. Buck circuit

For the buck converter [18],

$$
V_{0(B u c k)}=D_{(B u c k)} \cdot V_{\text {in }(B u c k)}
$$

where:

$V_{0 \text { (Buck) }}$ is the output voltage.

$D_{(\text {Buck })}$ is the duty cycle which is the ratio of the output to the input.

$V_{\text {in }(B u c k)}$ is the input voltage.

Also,

$$
I_{\text {in }(\text { Buck })}=D_{(\text {Buck })} \cdot I_{0(B u c k)}
$$

where:

$I_{\text {in }(B u c k)} \quad$ is the input current 
$I_{0 \text { (Buck) }}$ is the output current

The switch is controlled by a signal which will help to control the output voltage [18]. Buck converter can work in two modes of operation, switch ON mode and switch off mode. At the closed position of the switch as in Figure 2, the input voltage will be divided between inductor and the load. Therefore, the energy in the inductor will increase. While at the open position of the switch in Figure 3 , the inductor will discharge the energy to the load. Here, the switch is transistor that will be ON or OFF according to the gate signal. ON switch, produces the input voltage which is the sum of the inductor voltage and load voltage. In OFF switch, the inductor voltage is equal to the resistor voltage. Therefore, the inductor is the source at OFF switch. Also, in this converter the capacitor is used to decrease the output voltage ripple as well as the filtering of currents harmonic [19]. In addition to that, the freewheeling diode is utilized to transfer the energy from inductor to the load.

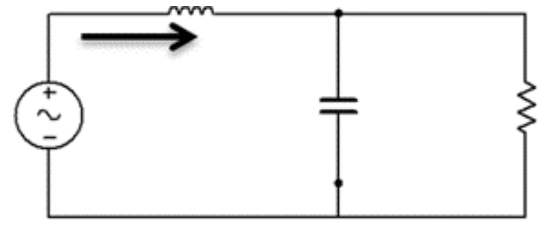

Figure 2. ON mode

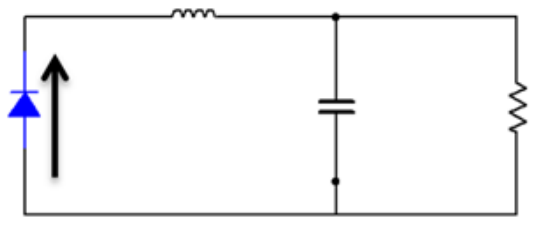

Figure 3. OFF mode

\section{THE PROPOSED CONTROLLERS}

Different controllers have been proposed in this paper. Every controller will control the duty cycle of the DC/DC buck converter as shown in Figure 4.

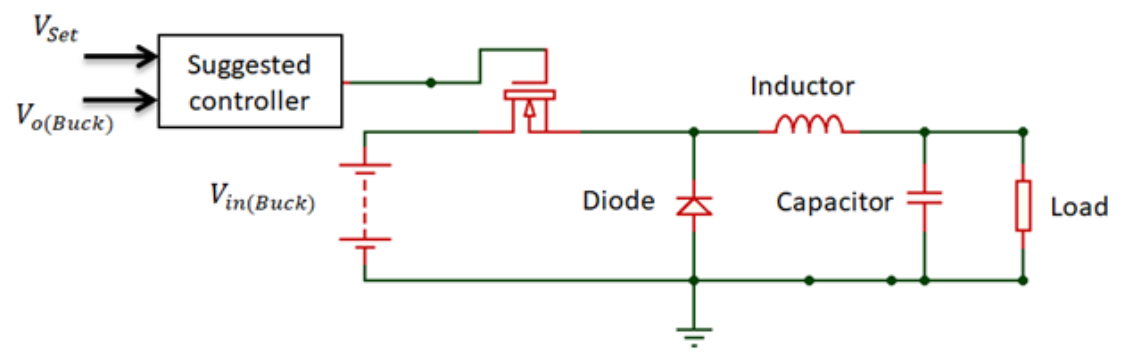

Figure 4. Control loop

\subsection{Proportional, integral, and derivative controller}

In most projects of process control, PID controller is used due to it is a simple in operation and its rendering is convinced [20]. In order to arrange the performance of this controller, its parameters can be adapted which are proportional, integral, derivative [21]. These parameters are optimized using different methods then,

$$
D_{(\text {Buck })}=K_{p} e+K_{i} \int e d t+K_{d} \frac{d e}{d t}
$$

The PID is tuned according to [22]; large positive input to the PID means the $K_{p}$ should be big, then $K_{i}$ small, as well as $K_{d}$, thus rapid the output of the system; very small input, produces small $K_{p}$, large $K_{i}$ and $K_{d}$, in that case the overshoot will be reduced by output and the response will be fast. That is why it should use another intelligent method. The MATLAB simulation of the PID controller is shown in Figure 5.

\subsection{The proposed fuzzy logic controller}

Fuzzy logic controller (FLC), is a controller used in different areas and applications such as the industrial, dish washes, and Televisions. FLC utilized the linguistic form rather than using the mathematical form for knowledge [23]. It is simple and low cost so it widely used especially for nonlinear systems [24]. Fuzzy controller consists of the following parts

- $\quad$ The fuzzifier. 
- $\quad$ The rule base.

- The defuzzifier.

In the fuzzifier stage, the data of the input will convert to the fuzzy values. Then the second stage is transfer of the fuzzy values to the (IF) and (THEN) rules. In this stage there is also a membership function in the system like Gaussian, Trapezoidal, and triangle. While the decision making will decide the output values. Figure 6 shows the fuzzy logic structure. While the fuzzy editor in MATLAB is shown in Figure 7.

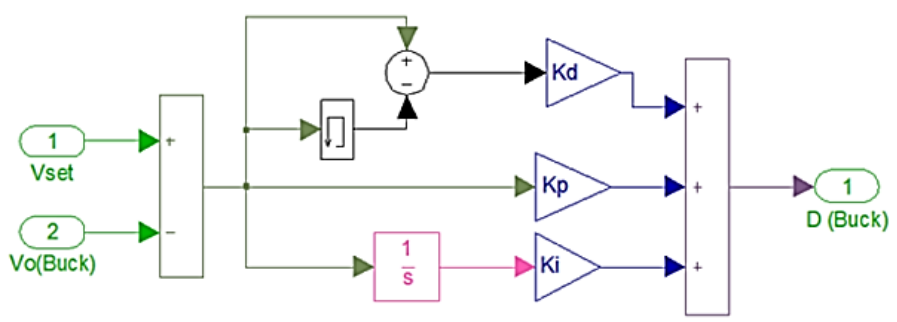

Figure 5. PID simulation

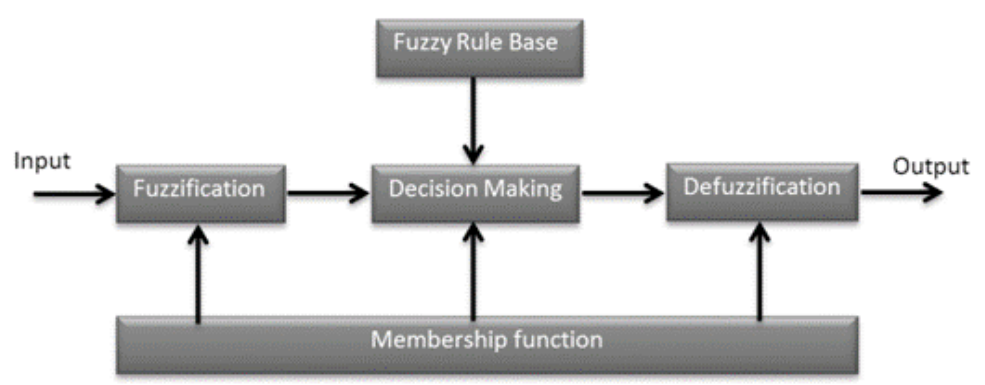

Figure 6. Fuzzy system

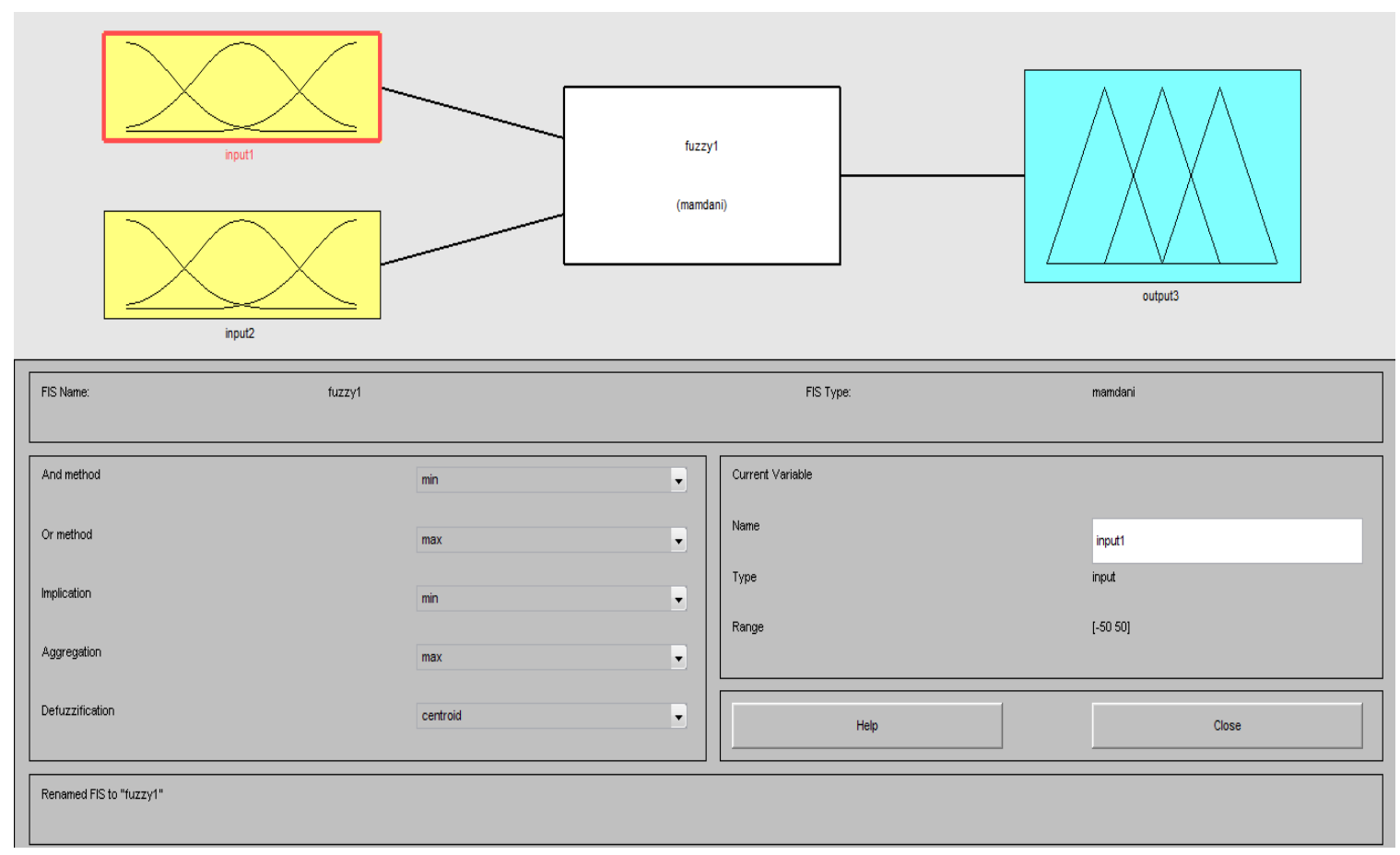

Figure 7. Fuzzy editor of fuzzy controller 


\subsection{Fuzzy supervisory-PID controller}

The fuzzy supervisory-PID (FSC-PID) [25] sort endeavors to give nonlinear activity for the controller utilizing fuzzy reasoning and the parameters of the PID are adjusted dependent on a fuzzy inference system. This controller consists of two parts, fuzzy and PID. In this system, the controller is the PID control, while the role of fuzzy is to control the PID through its parameters. MATLAB simulation for this type is shown in Figure 8.

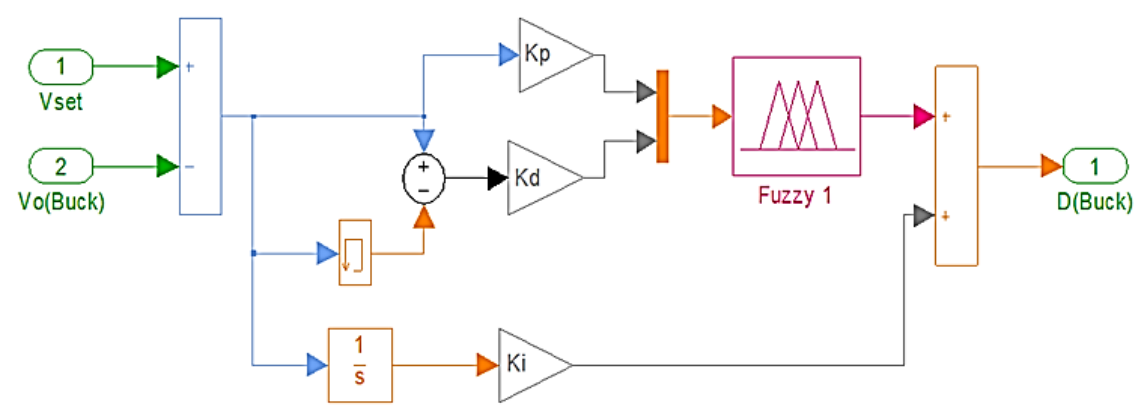

Figure 8. FSC-PID simulation

\section{SIMULATION RESULTS}

All the results have been done using laptop Dell with Windows 7 Ultimate operating system , where the CPU is Intel Core i5 2.5 GHz, RAM is 4 GB. The work is done using MATLAB R2008a. Thus, the buck converter has been simulated using MATLAB as shown in Figure 9.

The values of the component of the DC/DC converter are $R_{0}=40 \Omega$, Inductor $=40 \mathrm{mH}$, and Capacitor $=4 \mu F$. First, control the buck converter using PID controller as shown in Figure 10. Where $K_{p}=$ $100, K_{i}=10, K_{d}=0.01$ which are calculated by try and error method for the best values. Second, fuzzy controls the buck converter as shown in Figure 11. In this case triangle membership function is used. Finally, fuzzy supervisory-PID is presented to control the DC/DC converter as shown in Figure 12.

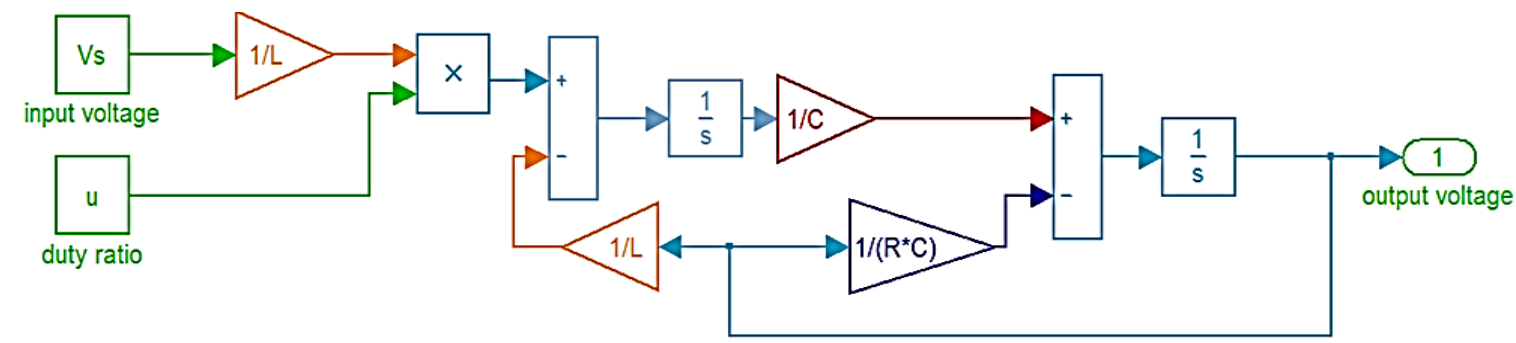

Figure 9. Simulink model of buck DC/DC converter

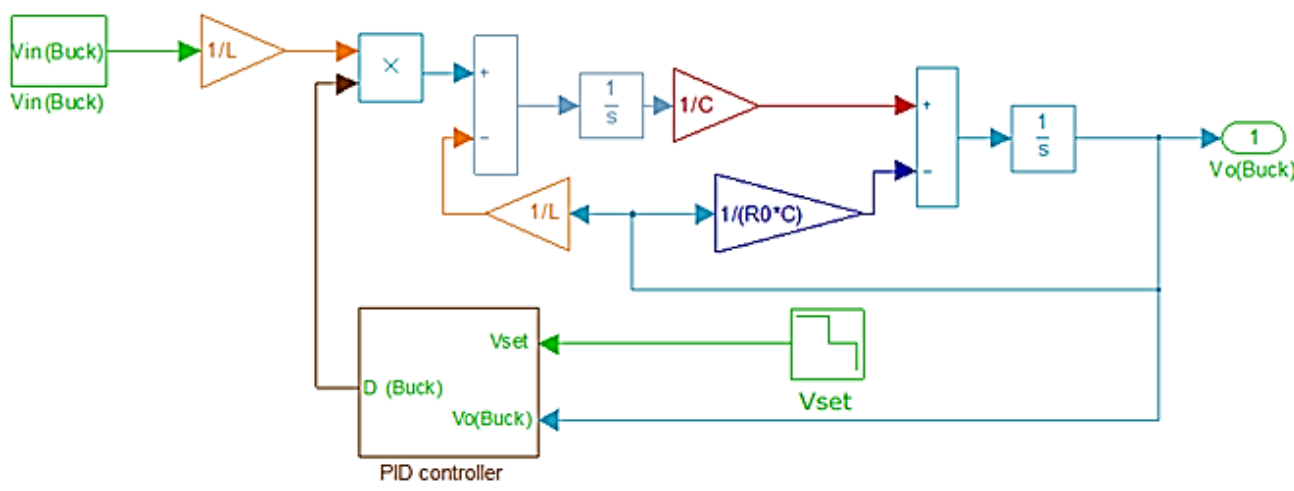

Figure 10. Buck converter controlled by PID 


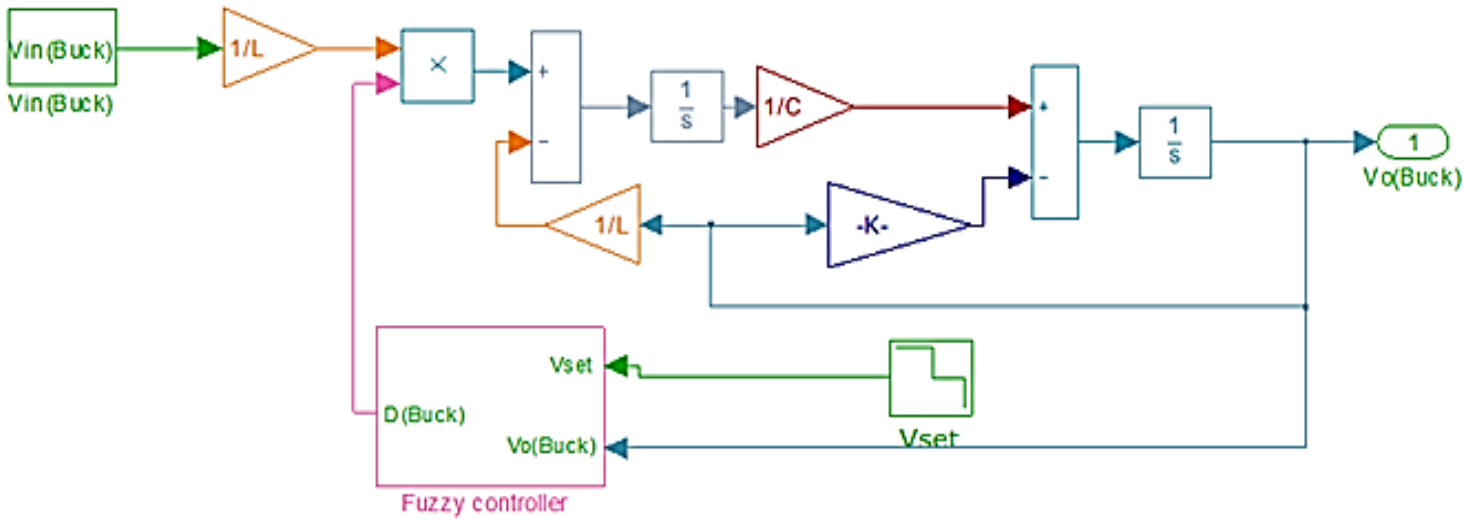

Figure 11. Buck converter controlled by fuzzy

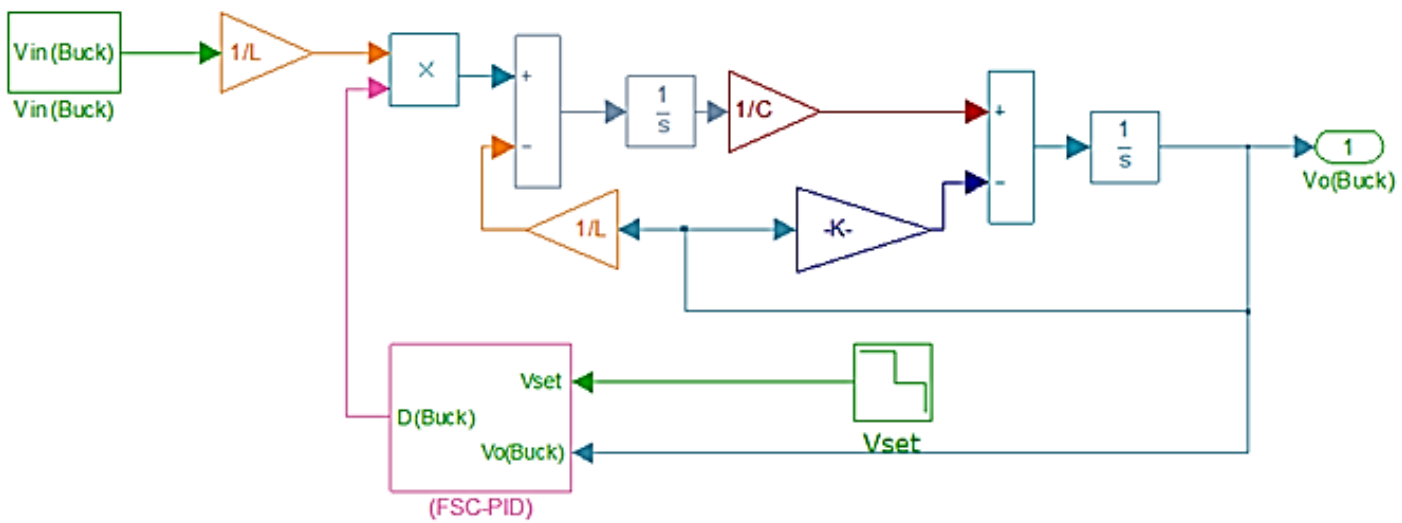

Figure 12. Buck converter controlled by fuzzy supervisory-PID

In order to prove the ability of the controllers to track and control the duty cycle of the proposed DC/DC converter, the reference voltage has been taken in two cases while $V_{\text {in (Buck) }}$ is kept constant at $20 \mathrm{~V}$.

Case 1: When $V_{\text {set }}=15 \mathrm{~V}$

Figure 13 shows $\boldsymbol{V}_{\text {set }}$ with different time instants. Hence, PID controller adjusts the duty cycle of converter. Here, the ripple is high with steady state error which is illustrated in Figure 14. In the fuzzy controller part, as given in Figure 15, the ripple is less than before but with big settling time. In Figure 16 the fuzzy supervisory-PID controls the converter with excellent results and very fast response which outperforms the others in terms of the error. In Figure 17 all controllers have been compared and illustrated in one figure.

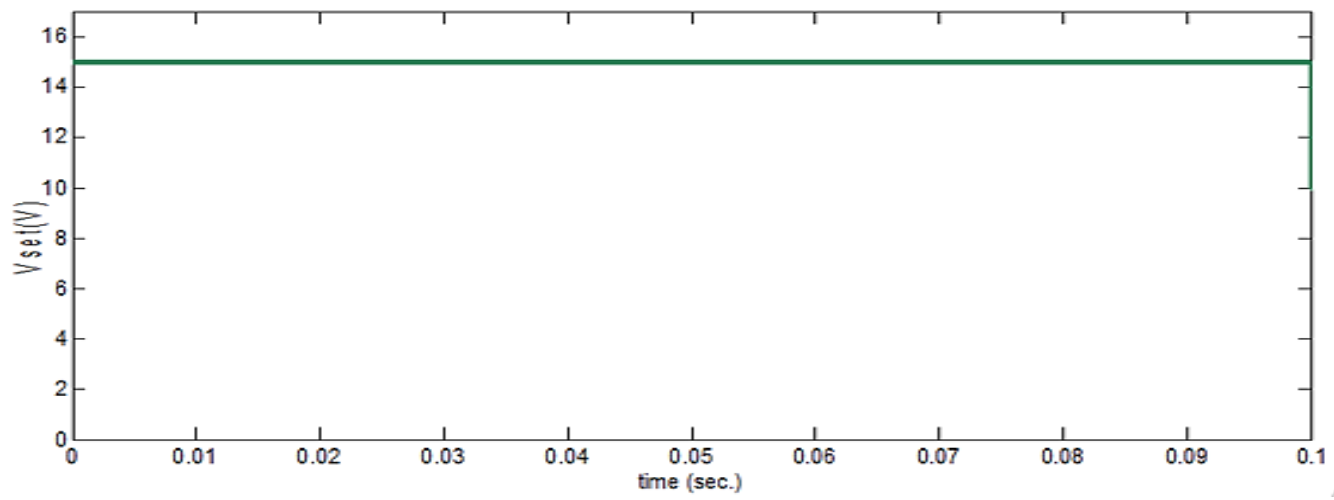

Figure 13. $V_{\text {set }}$ representation

Int J Artif Intell, Vol. 10, No. 4, December 2021: 847 - 857 


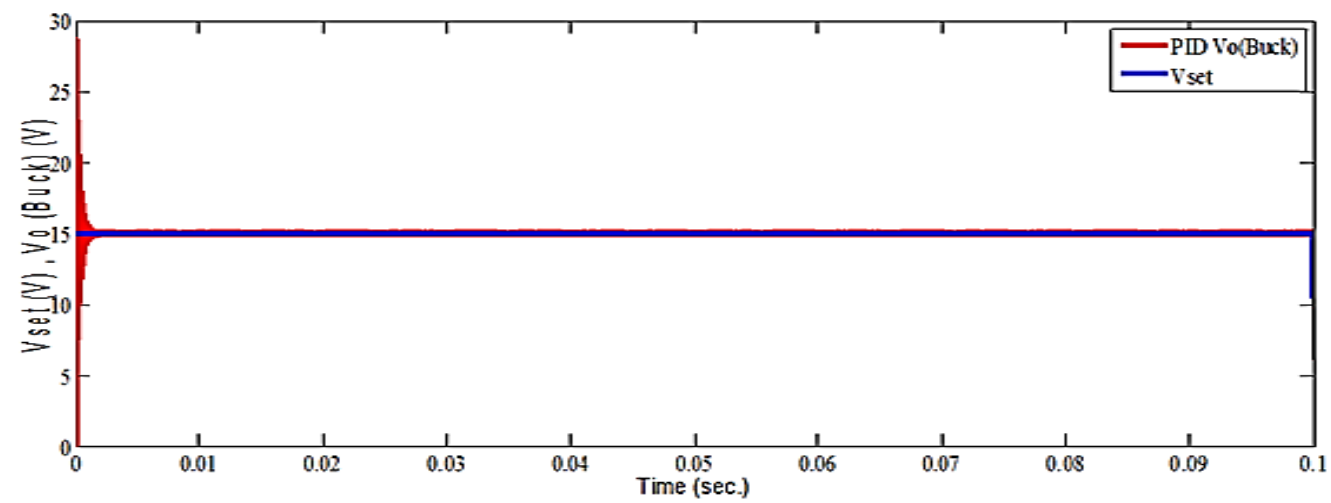

Figure 14. The output response with PID only

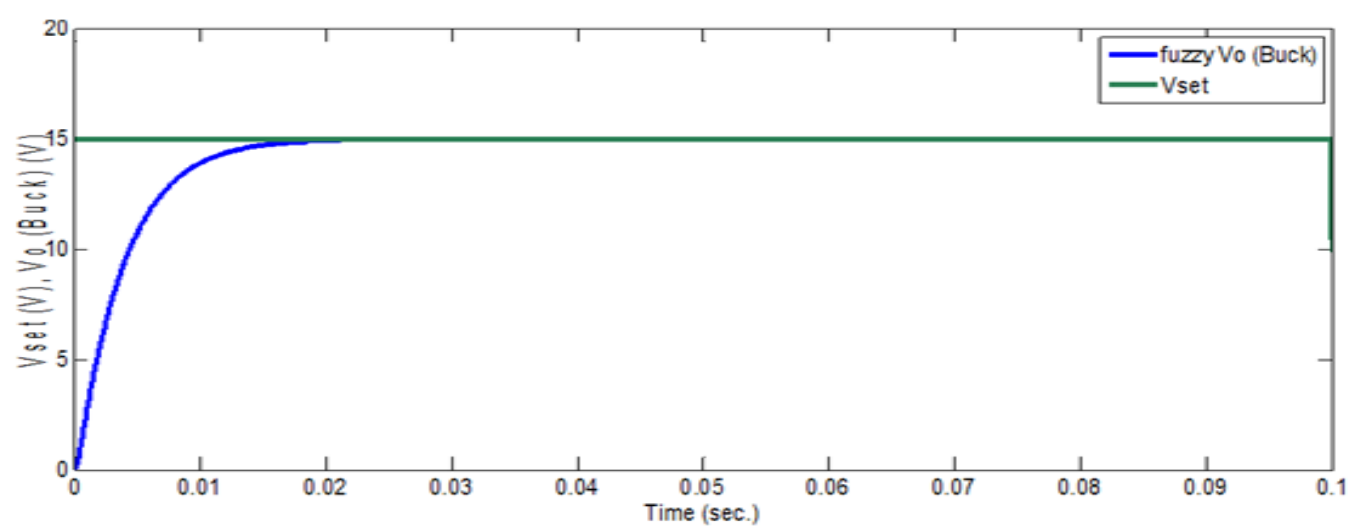

Figure 15. The output response with fuzzy only

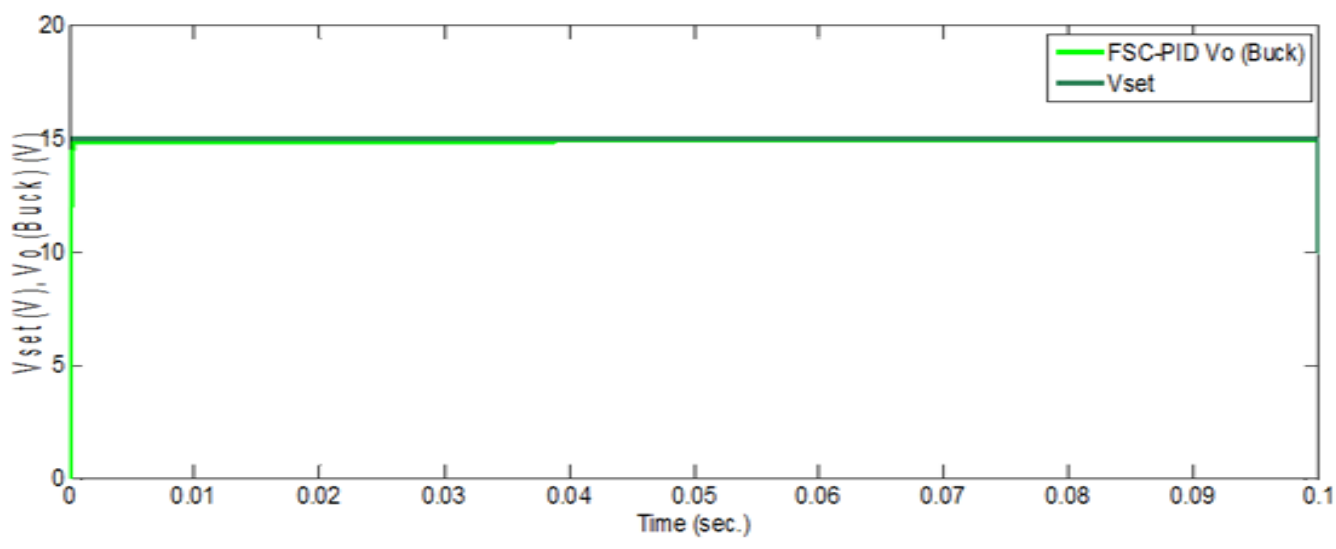

Figure 16. The output response with fuzzy supervisory-PID only

Case 2: When $V_{\text {set }}=5,10$, and $15 \mathrm{~V}$

The graph of $\boldsymbol{V}_{\text {set }}$ is presented in Figure 18. As shown in Figure 19, the controller is still not able to follow the reference purely and need improve by other controllers. In Figure 20, the fuzzy controller track the set voltage, however the settling time is larger compares to the rest controllers. Fuzzy supervisory-PID has good performance if it is compared with the two pervious controllers as in Figure 21. With different steps of $V_{\text {set }}$, the controllers are compared in the same plot as shown in Figure 22. Finally, table 1 presents the steady state values. 


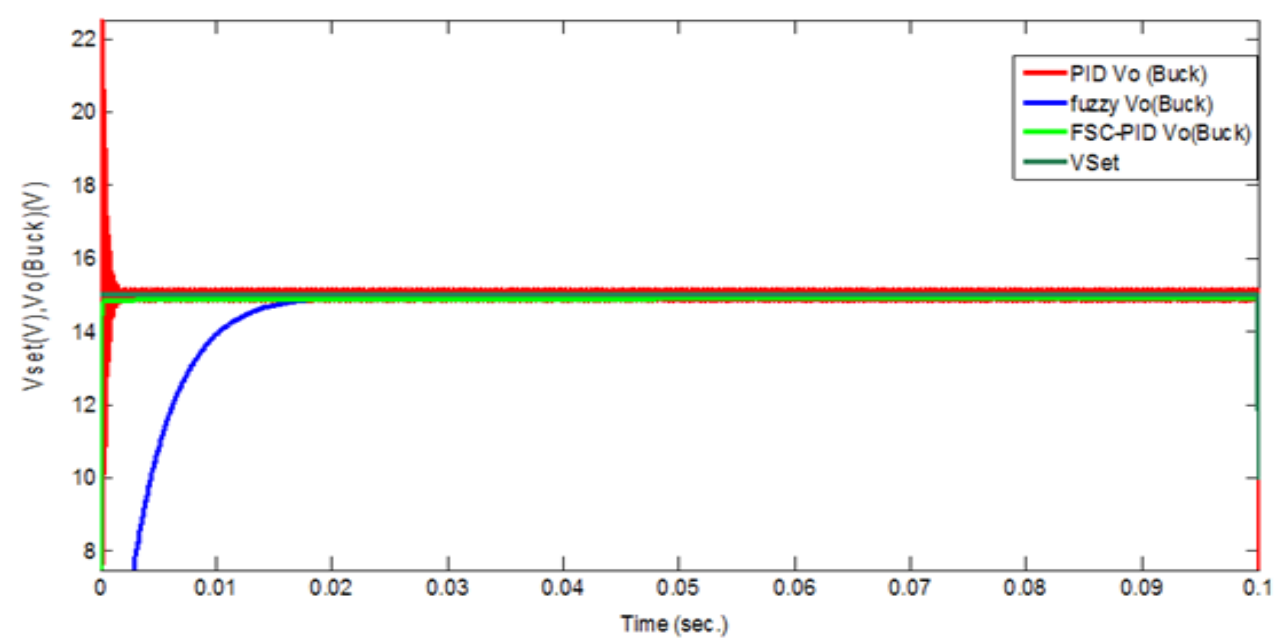

Figure 17. The output response with all proposed controllers

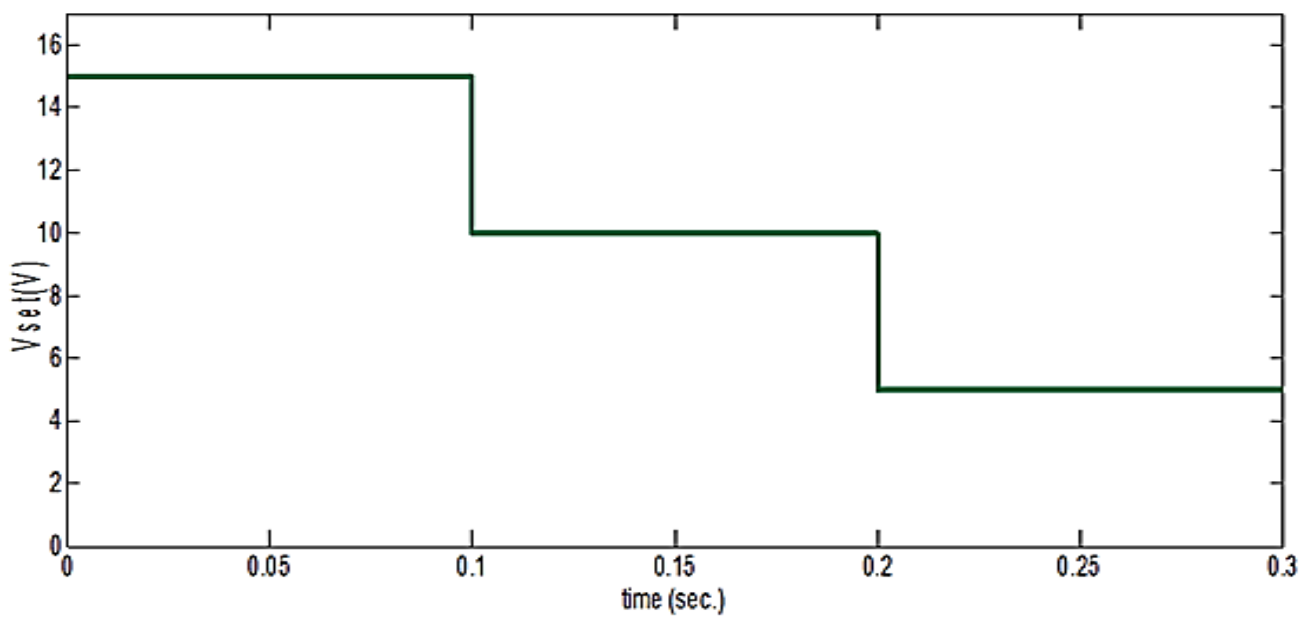

Figure 18. $V_{\text {set }}$ for case 2

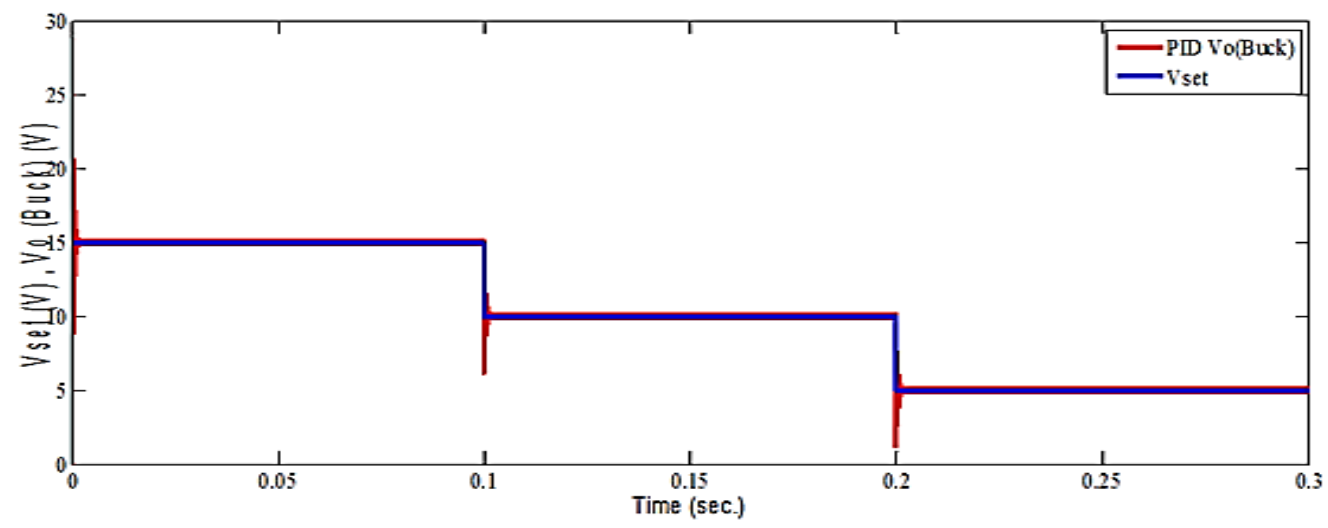

Figure 19. The output response using PID with different values of $V_{\text {set }}$ 


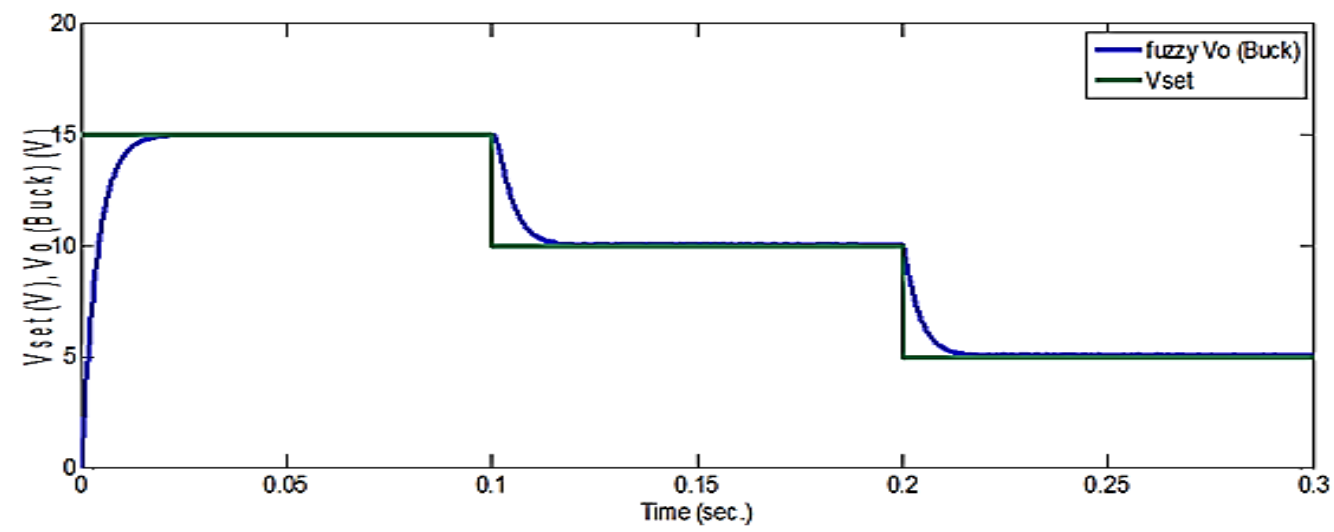

Figure 20. The output response using fuzzy with different values of $V_{\text {set }}$

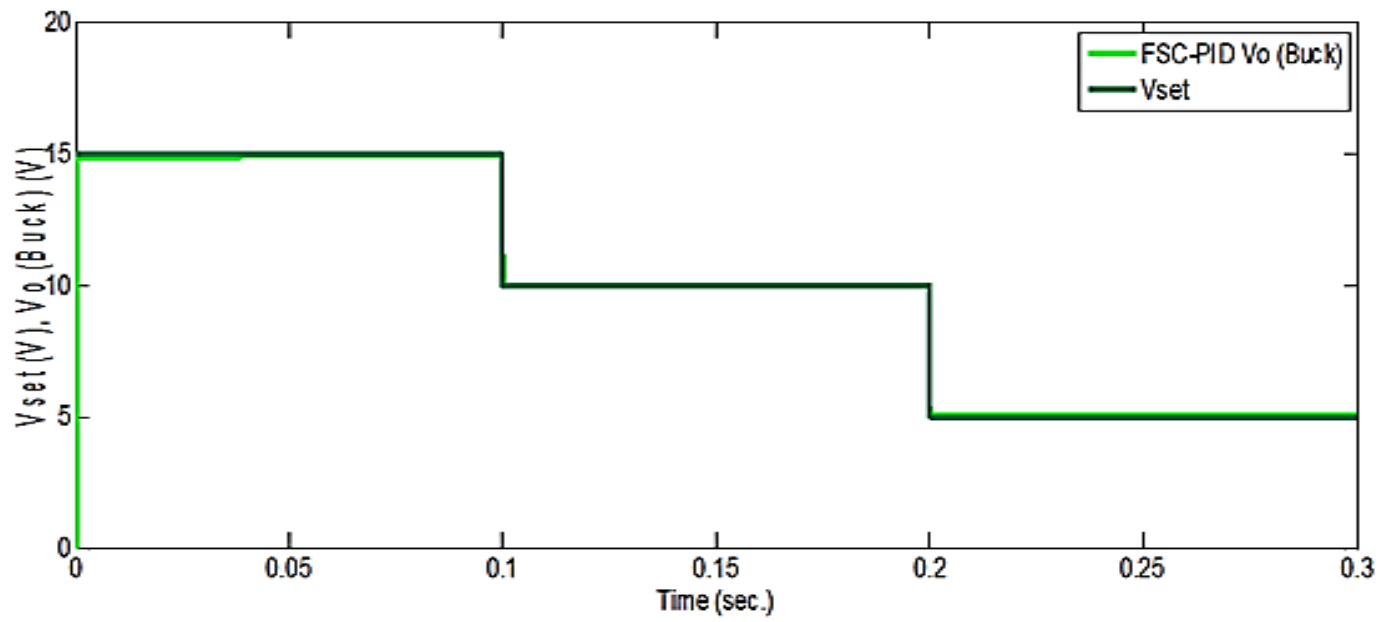

Figure 21. The output response using fuzzy supervisory-PID with different values of $V_{\text {set }}$

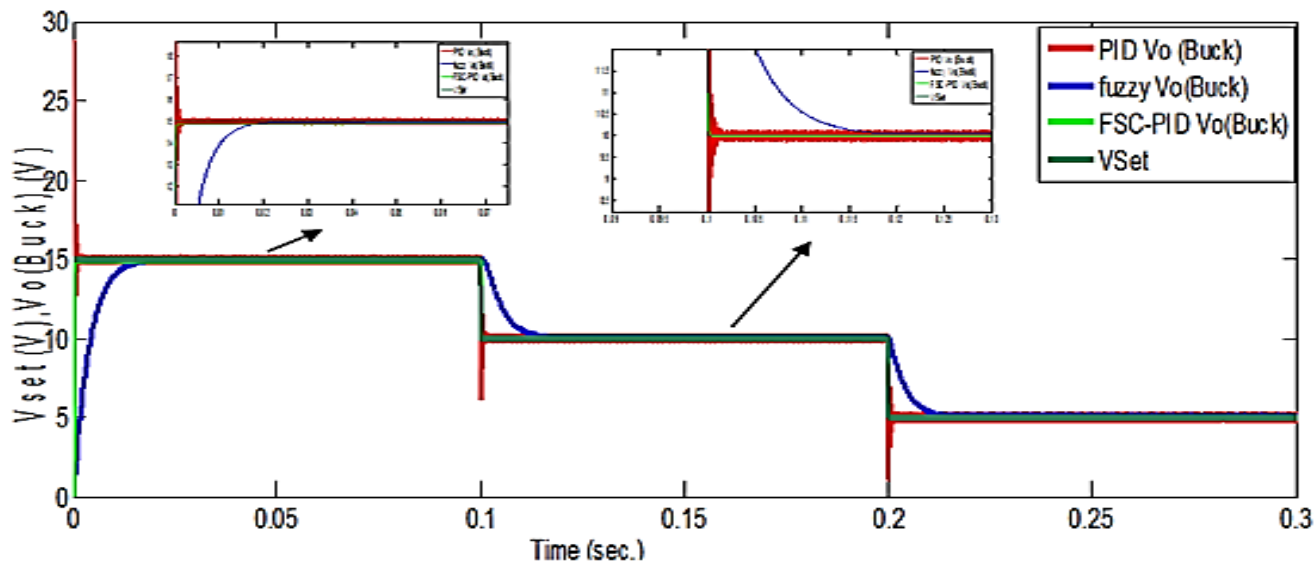

Figure 22. The output response with all proposed controllers

Table 1 . The steady state values for different set points

\begin{tabular}{cccc}
\hline$V_{\text {set }}(\mathrm{V})$ & PID $V_{0(\text { Buck })}(\mathrm{V})$ & Fuzzy $V_{0(B u c k)}(\mathrm{V})$ & FSC-PID $V_{0(\text { Buck })}(\mathrm{V})$ \\
\hline 15 & $14.85-14.14$ & 15 & 15 \\
10 & $9.9-10.1$ & 9.999 & 10 \\
5 & $4.95-5.4$ & 5.999 & 5 \\
\hline
\end{tabular}




\section{CONCLUSION}

In this work, various control techniques have been introduced to control the switching of the buck converter. Even if the controllers are competitive, but FSC-PID controller outperforms them in all its performance. The results are done using MATLAB software. The artificial intelligent control is used as well as PID control. Where the PID controller is used alone, then fuzzy logic controller, after that fuzzy-PID controller is implemented. The set voltage varied from $(5,10$, and 15$)$ to test the ability of the controllers to do the job.

\section{ACKNOWLEDGEMENTS}

Many thanks for everybody in Southern Technical University how help us to complete this paper.

\section{REFERENCES}

[1] D. H. Muhsen, A. B. Ghazali, T. Khatib, and I. A. Abed, "Extraction of photovoltaic module model's parameters using an improved hybrid differential evolution/electromagnetism-like algorithm," Solar Energy, vol. 119, pp. 286297, 2015, doi: 10.1016/j.solener.2015.07.008.

[2] I. A. Abed, "An improved technique based on firefly algorithm to estimate the parameters of the photovoltaic model," Iraqi Journal for Electrical and Electronic Engineering, vol. 12, no. 2, pp. 137-145, 2016, doi: $10.33762 /$ eeej.2016.118288.

[3] I. A. Abed, "Using firefly optimization method to extract the parameters of photovoltaic model system," Journal University of Kerbala, vol. 15, no. 4, pp. 280-293, 2017.

[4] J. D. Tan, M. Dahari, S. P. Koh, Y. Y. Koay, and I. A. Abed, "A new experiential learning electromagnetism-like mechanism for numerical optimization," Expert Systems with Applications, vol. 86, pp. 321-333, 2017, doi: 10.1016/j.eswa.2017.06.002

[5] J. D. Tan, M. Dahari, S. P. Koh, Y. Y. Koay, and I. A. Abed, "An improved electromagnetism-like algorithm for numerical optimization,” Theoretical Computer Science, vol. 641, pp. 75-84, 2016, doi: 10.1016/j.tcs.2016.05.045.

[6] I. A. Abed, "Photovoltaic parameters identification using optimization algorithm," University of Thi-Qar Journal, vol. 12, no. 2, pp. 47-64, 2017.

[7] M. B. U. Patil, "Design of fuzzy based controlling system for buck converter," International Journal of Advanced Research in Computer Engineering and Technology (IJARCET), vol. 4, no. 6, pp. 2730-2733, 2015.

[8] J. S. Martinez, D. Hissel, and M. C. Péra, "Type-2 fuzzy logic control of a DC/DC buck converter," IFAC Proceedings Volumes, vol. 8, pp. 103-108, 2012, doi: 10.3182/20120902-4-fr-2032.00020.

[9] J. K. Prasad, T. K. Kumar, and A. A. Reddy, "Design of fuzzy logic controller for buck converter to improve power quality," International Journal of Advanced Information Science and Technology, vol. 27, no. 27, pp. 76-80, 2014.

[10] P. Maji, P. G. K. Panda, and P. P. K. Saha, "Performance analysis for DC-DC buck converter with fuzzy and robust controller," International Journal of Advanced Research in Electrical, Electronics and Instrumentation Engineering, vol. 4, no. 5, pp. 4127-4135, 2015, doi: 10.15662/ijareeie.2015.0405056.

[11] A. Pandey and D. Singh, "A buck converter based on PID controller for voltage step-down application," International Journal of Science and Research (IJSR), vol. 4, no. 12, pp. 1164-1167, 2015, doi: 10.21275/v4i12.nov152179.

[12] M. B. Poodeh, S. Eshtehardiha, and M. R. Zare, "Application of fuzzy logic to control the DC-DC converter," 7th WSEAS International Conference on Electric Power Systems, High Voltages, Electric Machines, Venice, Italy, 2007, pp. 34-39.

[13] J. I. Corcau and L. Dinca, "Fuzzy logic control for a DC to DC buck converter," cientific Research and Education in the Air Force-AFASES 1, vol. 18, no. 1, pp. 233-238, 2016, doi: 10.19062/2247-3173.2016.18.1.31.

[14] S. Kanta, B. Plangklang, and W. Subsingha, "Design, modelling and simulation of a PID controller for buck boostand cuk converter," Energy Procedia, vol. 56, no. C, pp. 604-609, 2014.

[15] B. Safarinejadian and F. Jafartabar, "Hybrid fuzzy logic controllers for buck converter," Proceedings of the 2012 International Conference on Artificial Intelligence and Image Processing, 2012, pp. 6-7.

[16] C. P. Ugale, R. B. Dhumale, and V. V. Dixit, "DC-DC converter using fuzzy logic controller," International Research Journal of Engineering and Technology (IRJET), vol. 2, no. 4, pp. 593-596, 2015.

[17] Z. B. Duranay and H. Guldemir, "Study of fuzzy logic control of Dc-Dc buck converter," Turkish Journal of Science \& Technology, vol. 12, no. 2, pp. 23-31, 2017.

[18] S. Kanta, B. Plangklang, and W. Subsingha, "Digital PID controller design for DC-DC buck converter," Energy Procedia, vol. 56, no. C, pp. 604-609, 2014.

[19] E. R. C. S. Madhukiran, P. S. Thota, B. Sridhar, and K. Dileesh, "Control of buck converter by polynomial, PID and PD controllers," 2012 Asia Pacific Conference on Postgraduate Research in Microelectronics and Electronics, 2012, pp. 94-99, doi: 10.1109/PrimeAsia.2012.6458634.

[20] O. Katsuhiko, "Modern control engineering (Ogata 3rd Edition)," Perpustakaan Himpunan Mahasiswa Elektro Universitas Siliwangi, 1996.

[21] K. M. Elbayomy, Z. Jiao, and H. Zhang, "PID controller optimization by GA and its performances on the electrohydraulic servo control system," Chinese Journal of Aeronautics, vol. 21, no. 4, pp. 378-384, 2008, doi: 10.1016/S1000-9361(08)60049-7. 
[22] H. Elaydi, I. Abu Hardouss, and A. Alassar, "Supervisory fuzzy control for 5 DOF robot arm," International Journal of Science and Advanced Technology, vol. 2, no. 7, pp. 1-6, 2012.

[23] R. F. Ningrum, R. R. A. Siregar, and D. Rusjdi, "Fuzzy Mamdani logic inference model in the loading of distribution substation transformer SCADA system," IAES International Journal of Artificial Intelligence (IJ-AI), vol. 10, no. 2, pp. 298-305, 2021, doi: 10.11591/ijai.v10.i2.pp298-305.

[24] K. F. Hussein, I. Abdel-Qader, and M. K. Hussain, "Hybrid fuzzy PID controller for buck-boost converter in solar energy-battery systems," 2015 IEEE International Conference on Electro/Information Technology (EIT), 2015, pp. 70-75, doi: 10.1109/EIT.2015.7293323.

[25] M. Al-Shabi, C. Ghenai, M. Bettayeb, F. F. Ahmad, and M. E. H. Assad, "Estimating pv models using multi-group salp swarm algorithm," IAES International Journal of Artificial Intelligence (IJ-AI), vol. 10, no. 2, pp. 398-406, 2021, doi: 10.11591/ijai.v10.i2.pp398-406.

\section{BIOGRAPHIES OF AUTHORS}
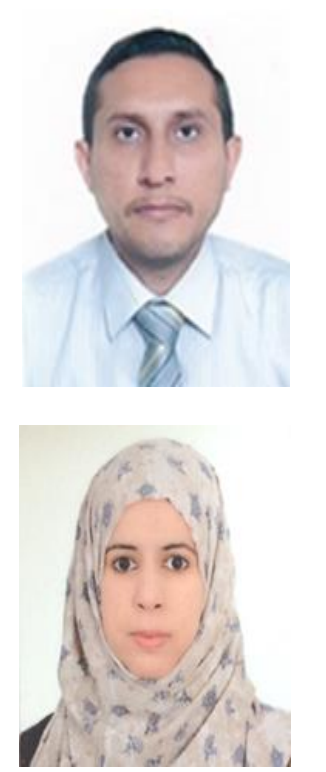

Issa Ahmed Abed received his BSc. and MSc. in Control and Computing from the Department of Electrical Engineering, University of Basrah, Iraq in 2002 and 2005, respectively. While his $\mathrm{PhD}$ is also in Control and Computing from University Tenaga Nasional, Malaysia in 2014. Currently, he is an Asst. Prof. and the head of control and automation department at Engineering Technical College Basrah, Southern Technical University, Iraq. His areas of interest include Artificial Intelligence, Solar energy, control systems, robotics, and image processing.

Samar Hameed Majeed received her MSc. In Electrical Engineering from Basrah University in 2011. She is currently an Asst. lecturer in Southern Technical University. Her research interests in machine and power electronics design and analysis, and intelligent control. 